American Journal of Infectious Diseases 1 (1): 43-49, 2005

ISSN 1553-6203

(C) 2005 Science Publications

\title{
Evidences of Apoptosis in Hepatitis C Virus-Infected Hepatocytes and Peripheral Blood Monocuclear Cells in the Absence of Liver Injury
}

\author{
${ }^{1}$ Viviana Falcón, ${ }^{1}$ Nelson Acosta-Rivero, ${ }^{4}$ Mineko Shibayama, ${ }^{4}$ Jose Luna-Munoz \\ ${ }^{4}$ Magdalena Miranda-Sanchez, ${ }^{1}$ María-C de la Rosa, ${ }^{1}$ Ivón Menéndez, ${ }^{2}$ Waldo García, ${ }^{2}$ Bienvenido Gra \\ ${ }^{1}$ Santiago Dueñas-Carrera, ${ }^{1}$ Deliana Lopez, ${ }^{3}$ Maritza González Bravo, ${ }^{1}$ Celia Fernández-Ortega \\ ${ }^{1}$ Dionne Casillas, ${ }^{1}$ Juan Morales, ${ }^{4}$ Juan Kouri, ${ }^{4}$ Victor Tsutsumi \\ ${ }^{1}$ Biomedicine Division, Center for Genetic Engineering and Biotechnology \\ P.O. Box 6162, C.P. 10600, Havana \\ ${ }^{2}$ Institute of Gastroenterology, C.P. 10400, Havana \\ ${ }^{3}$ National Center for Scientific Research, P.O. Box 6990, Havana \\ ${ }^{4}$ Centro de Investigación y de Estudios Avanzados (CINVESTAV-IPN), México City, México
}

\begin{abstract}
Understanding the mechanism of Hepatitis C Virus (HCV) pathogenesis is an important part of HCV research. In this study, the presence of apoptosis in HCV-infected liver and Peripheral Blood Mononuclear Cells (PBMC) from patients positive for anti-HCV antibodies and negative for serum HCV-RNA was investigated. The samples obtained from 21 patients were studied by in situ Hybridization (ISH), Immunofluorescence, TUNEL reaction and caspase 3 activation assays. The findings show that both DNA fragmentation by TUNEL assay and activation of caspase 3 were detected in hepatocytes from patients histologically confirmed as bearing chronic hepatitis or with abnormal ALAT or GGTP as well as in patients with no histological evidences of chronic hepatitis and normalization of transaminases. Apoptotic cells were also detected in PBMC samples by the TUNEL assay. ISH analysis of liver biopsies and PBMC samples showed both positive and negative strands of the HCV genome localized in some cells showing nuclear characteristics of apoptosis such as chromatin margination, condensation and fragmentation. These typical morphological changes of apoptotic cell death were also observed in some hepatocytes showing reaction products suggestive of $\mathrm{HCcAg}$. Data suggest that under certain conditions HCV induces apoptosis in the absence of liver injury. Induction of apoptosis in $\mathrm{HCV}$-infected cells may interfere with viral replication, which may lead to undetectable levels of HCV-RNA in serum.
\end{abstract}

Key words: HCV, liver biopsy, PBMC, HCV-RNA, confocal microscopy, apoptosis

\section{INTRODUCTION}

Hepatitis $\mathrm{C}$ virus (HCV) is the major cause of nonA, non-B hepatitis that infects 170 million people worldwide ${ }^{[1]}$. Persistent infection occurs in more than $70 \%$ of people infected with $\mathrm{HCV}, 20 \%$ of which progress to liver cirrhosis ${ }^{[2]}$. $\mathrm{HCV}$ is an enveloped, positive-strand RNA virus that belongs to the Flaviviridae family. The viral genome $(9.6 \mathrm{~kb})$ is translated into a single polyprotein of 3,000 amino acids (aa). The viral products (core, E1, E2, NS2, NS3, NS4A, NS4B, NS5A and NS5B) are processed from this polyprotein by a combination of host and viral proteases. The amino-terminal part is cleaved by host cell proteases and its products, core $(\mathrm{HCcAg})$ and envelope (E1 and E2) proteins, are believed to be the major constituents of $\mathrm{HCV}$ virions ${ }^{[3]}$.

At present, there is no vaccine available to prevent $\mathrm{HCV}$ infection and current therapies are not optimal.
Multiple factors may influence the host-virus interaction in patients infected with $\mathrm{HCV}$ and these may result in diverse disease presentations. Since mechanisms of $\mathrm{HCV}$ infection remain unclear, characterization of these mechanisms is now a major issue for the development of new strategies for antiHCV treatment and prevention ${ }^{[4]}$.

Several assays such as in situ hybridization (ISH), immunohistochemistry (IHC) and immunofluorescence (IF) have been used for the localization of $\mathrm{HCV}$ genome and gene products inside HCV-infected cells ${ }^{[5]}$. Detection of $\mathrm{HCV}$ components in either the human liver or nonhepatic compartments such as PBMC is a useful tool in the determination of the pathogenesis of HCVassociated diseases. It has been suggested that apoptosis of liver cells may play a significant role in the pathogenesis of hepatitis C. However, the role of virusrelated apoptosis in hepatic injury in patients positive for anti-HCV antibodies and negative for HCV-RNA in 
serum is unclear. It is unknown whether HCV induces apoptosis directly or whether apoptosis is immunologically mediated.

Previously, it has been demonstrated that HCVRNA might be present in the liver and PBMC, in the absence of viral RNA and anti-HCV antibodies in serum $^{[6,8]}$. In addition, it has been shown that HCVRNA can persist at very low levels in the serum, PBMC and liver for many years after apparently complete spontaneous or antiviral therapy-induced resolution of chronic hepatitis $\mathrm{C}^{[9,10]}$. Recently, it has been shown the presence of HCV-RNA of both positive and negative polarity in hepatocytes and PBMC from patients positive for anti-HCV antibodies and negative for serum HCV-RNA ${ }^{[11]}$. In the present work, the presence of apoptosis in HCV-infected liver and PBMC from 21 of these patients was investigated..

\section{MATERIALS AND METHODS}

Patients and samples: The total number of 21 patients used in this study have been recently described ${ }^{[11]}$. They were serologically positive to third-generation $\mathrm{HCV}$ enzyme immunoassays (Tecnosuma International, Havana, Cuba). Besides, they were investigated after informed consent in writing was obtained. Liver needle biopsy samples were taken at the time of routine diagnostic biopsy from all patients. These 21 patients were selected based upon they showed negative detection of serum HCV-RNA by RT-PCR (Amplicor HCV Amplification Kit 2.0, Roche Diagnostic Systems,Inc) on the same day of the liver biopsy. In addition, all patients showed positive detection of intrahepatic HCV-RNA of both positive and negative polarity ${ }^{[11]}$. None was seropositive for markers of hepatitis B virus (HBV), hepatitis A virus and human immunodeficiency virus by enzyme immunoassay (Tecnosuma International, Havana, Cuba).

In addition, PBMC samples from 14 of these 21 selected patients taken on the same day of the liver biopsy were analyzed. They showed positive detection of HCV-RNA of positive and negative polarity ${ }^{[1]}$. A total 11 out of 21 patients showed no histological evidences of chronic hepatitis and had normal serum alanine aminotransferase (ALAT) or gamma-glutamyl transpeptidase (GGTP) levels for at least six month before the biopsy was performed.

Liver needle biopsy samples were taken from two HCV-uninfected healthy donor livers for transplantation purpose as negative controls. Moreover, PBMC samples from five healthy volunteers were used as negative controls.

PBMC were prepared by Ficoll-Hypaque (Lymphoprep) (Pharmacia, Uppsala, Sweden) gradient centrifugation, washed five times with $20 \mathrm{~mL}$ of phosphate-buffered saline (PBS) and then counted using a hemocytometer.
Antibodies and primers: The anti-HCcAg mouse monoclonal antibody $(\mathrm{mAb})$ SS-HepC.1 recognizing aa 5 to 35 of $\mathrm{HCcAg}$ was used for immunodetection studies $^{[12]}$.

The following synthetic probes corresponding to the highly conserved 5' noncoding region of HCV were used in this work:

* To detect the HCV-RNA of positive strand the biotin-labeled antisense probe (HCV-1) (5'- biotinGTTTATCCAAGAAAGGACCC-3', position 188207) was used.

* To detect the HCV-RNA of negative strand the biotin-labeled sense probe (HCV-2) (5'-biotinTTCACGCAGAAAGCGTCTAG-3', position 6382) was used.

For controls, an antisense biotin-labeled probe for rat prolactin mRNA (5'-biotinACATATCTGTATACAGGGTAG-3', position 63-82) was used.

These probes were synthesized and purified using conditions previously described ${ }^{[13]}$.

In situ hybridization (ISH) assay: Samples were immediately fixed with $4 \%$ paraformaldehyde in PBS at $4^{\circ} \mathrm{C}$ and then mounted on gelatine-coated glass slides and stored for 2 days at $-200^{\circ} \mathrm{C}$. The ISH assay was performed as previously reported ${ }^{[13]}$. Stained samples were coverslipped in Vectashield mountaing medium (Vector Laboratories, Inc. Burlingame, CA., USA), sealed with nail polish and viewed on a confocal laser scanning microscope.

The specificity of the ISH reaction was confirmed using experiments that involved: A-) hybridization of a section from the same liver biopsy or PBMC sample with a biotin-labeled probe having a sequence unrelated to HCV-RNA; B-) hybridization with the probes specific for HCV-RNA to either liver biopsy sections or PBMC samples obtained from $\mathrm{HCV}$-uninfected individuals.

Immunofluorescence staining: Samples were immediately fixed with 4\% paraformaldehyde in PBS at $4^{\circ} \mathrm{C}$ and then mounted on gelatine-coated glass slides and stored for 2 days at $-200^{\circ} \mathrm{C}$. Later on, mounted samples were hydrated for $10 \mathrm{~min}$ in PBS and incubated with $0.2 \%$ Triton $\mathrm{X}$ in PBS during $10 \mathrm{~min}$. To block non-specific antibody reaction, best results were obtained by incubating the sections with $0.2 \%$ bovine serum albumin (BSA) (free of IgG) (Sigma Chemical Co. St. Louis, Mo.USA), for $10 \mathrm{~min}$ at RT. After two washes in PBS-T, samples were incubated overnight at $4^{\circ} \mathrm{C}$ with the anti-HCcAg mAb (dilution 1:20 in PBS-T). Incubations were followed by washes with PBS-T. The second incubations were accomplished with FITC-conjugated 
anti-mouse IgG (dilutions 1:60 in PBS-T, Vector laboratories, Inc., Burlingame, CA., USA) for 1 hour at RT. After three washes with PBS-T the sections from all samples were counterstained with propidium iodide (dilution 1:1000, Vector laboratories, Inc. Burlingame CA., USA), followed by extensive washing in PBS-T. Immunostained samples were coverslipped in Vectashield mountaing medium (Vector Laboratories, Inc. Burlingame, CA., USA), sealed with nail polish and viewed on a confocal laser scanning microscope. Negative controls were performed by substituting the primary antibodies with normal mouse serum.

Determination of in situ cell death (TUNEL reaction) and detection of caspase 3 activation: Samples were immediately fixed with $4 \%$ paraformaldehyde in PBS at $4^{\circ} \mathrm{C}$ and then mounted on gelatine-coated glass slides and stored for 2 days at $200^{\circ} \mathrm{C}$. Both TUNEL reaction and detection of caspase 3 activation were performed as recently described ${ }^{[13]}$. Stained samples were coverslipped in Vectashield mountaing medium (Vector Laboratories, Inc. Burlingame, CA., USA), sealed with nail polish and viewed on either a confocal or immunofluorescence microscope.

Laser confocal scanning imaging and serial section collection: Samples were viewed with a 60x (NA 1.4) objective on a Nikon microscope with attached laser confocal scanning system MRC 600 (BioRad, Watfod). Ten to twelve fields were imaged from each sample. Four to fifteen serial optical z-sections (0.2-0.5 $\mu \mathrm{m}$ thick) were collected from each observed field using the dual channel imaging with filter $(554 \mathrm{~nm})$ for propidium iodide excitation and the filter $(494 \mathrm{~nm})$ for the fluorescein channel. Each series of confocal optical sections was scanned through a total of $25 \mu \mathrm{m}$. The resulting optical sections were fully projected onto twodimensional planes using the imaging processing system of the microscope (Camos package).

\section{RESULTS}

The presence of apoptotic cells in both liver biopsy and PBMC samples from patients positive for anti$\mathrm{HCV}$ antibodies and negative for serum HCV-RNA was studied. A standard test for apoptosis is the TUNEL (terminal deoxynucleotide transferasemediated dUTP nick end labelling) assay, which detects fragmented DNA. Thus, the presence of apoptotic hepatocytes in the liver biopsy specimens was analyzed using the TUNEL assay. Figure 1B shows a representative experimental demonstrating that some hepatocytes from $\mathrm{HCV}$-infected patients were undergoing apoptosis as indicated by dUTP incorporation. However, no sign of apoptosis was detected in hepatocytes from healthy individuals (Fig. 1A).
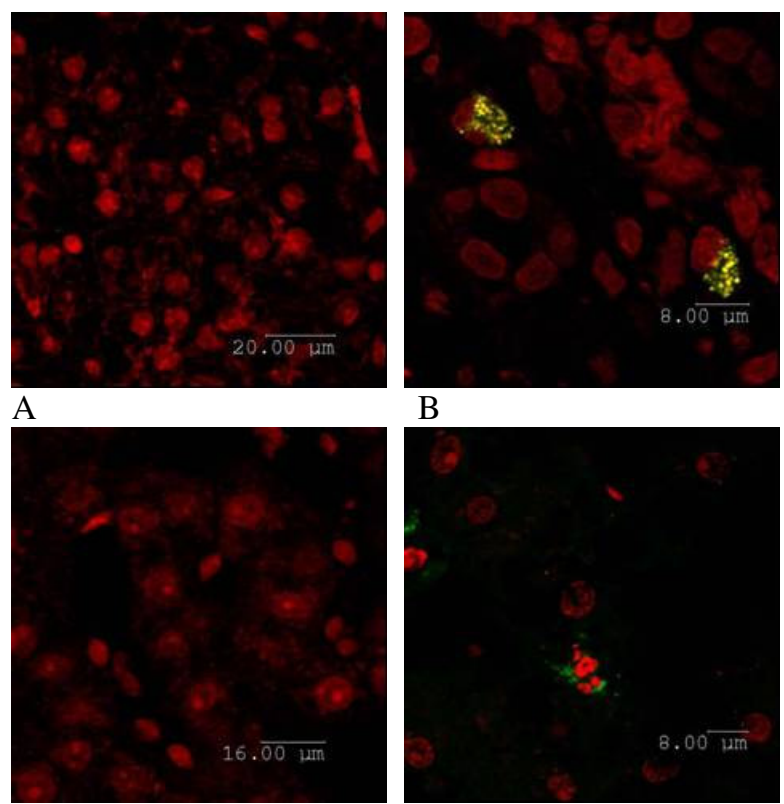

B

C
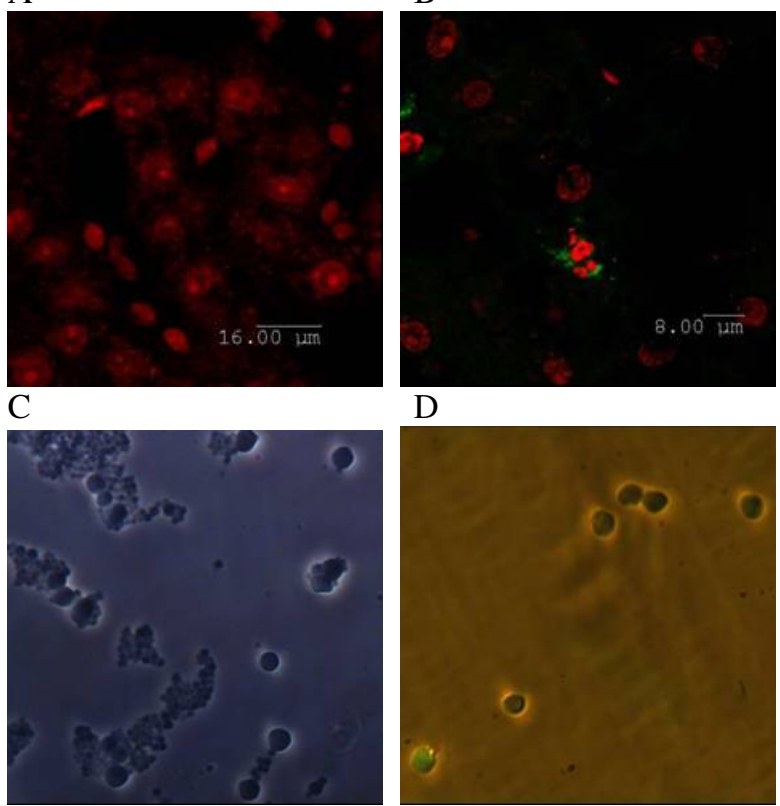

$\mathrm{D}$

E

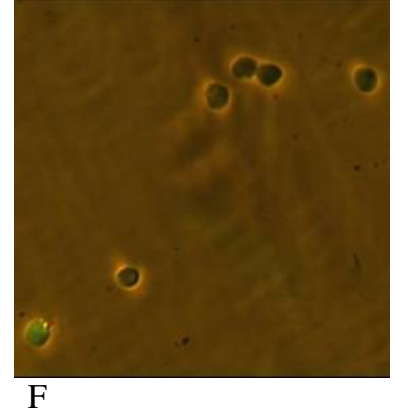

Fig. 1: Analysis of apoptotic hepatocytes and PBMC. A-D) Laser scanning confocal microscopy of either DNA fragmentation by TUNEL assay $(A, B)$ or caspase 3 activation $(C, D)$ in either liver biopsies from $\mathrm{HCV}$-infected patients $(\mathrm{B}, \mathrm{D})$ or from healthy individuals $(\mathrm{A}, \mathrm{C})$. Samples were viewed on a confocal microscope. E,F) Fluorescent staining of DNA fragmentation by TUNEL assay of PBMC from HCV-infected patients (F) and from healthy individuals (E). Samples were viewed on an immunofluorescence microscope (Bar $=20 \mu \mathrm{m}$ in $\mathrm{A} ; 16 \mu \mathrm{m}$ in $\mathrm{C} ; 8 \mu \mathrm{m}$ in $\mathrm{B}, \mathrm{D})$

It is known that the caspase activation assay detects apoptosis at an early stage before DNA fragmentation occurs. Therefore, the activation of caspase 3 was investigated to verify the detection of apoptotic hepatocytes. Almost no immunoreativity was evident in healthy liver tissue (Fig. 1C). In contrast, liver tissue from $\mathrm{HCV}$-infected patients clearly showed hepatocytes that stained positively for active caspase 3 (Fig. 1D).

On the other hand, the presence of apoptotic cells in PBMC samples was assessed by the TUNEL assay. Figure $1 \mathrm{~F}$ shows a representative experimental demonstrating positive reaction in some PBMC from 


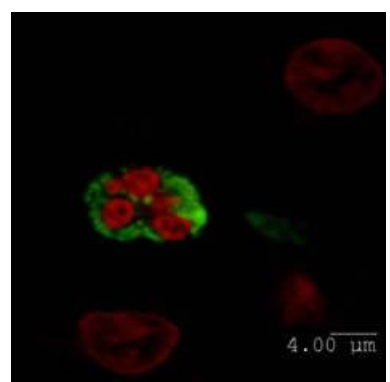

A

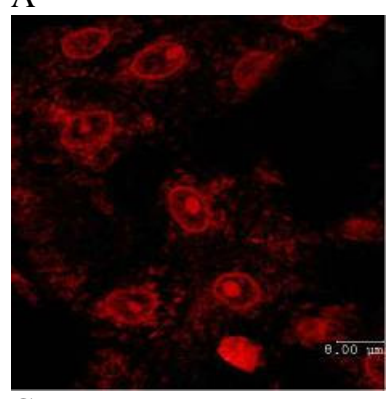

$\mathrm{C}$

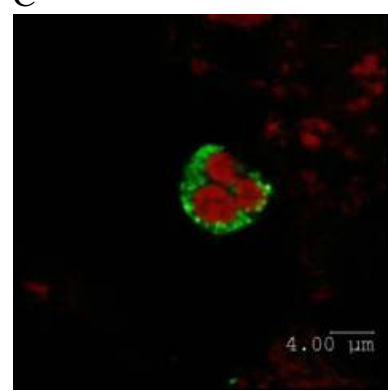

$\mathrm{E}$

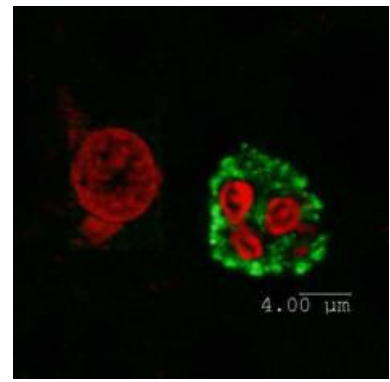

B

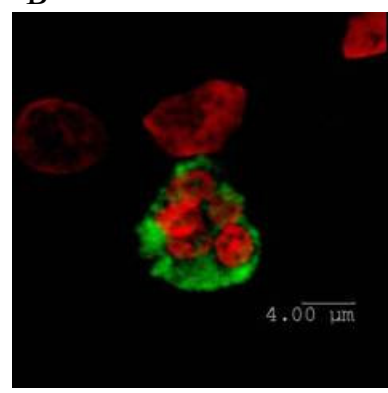

$\mathrm{D}$

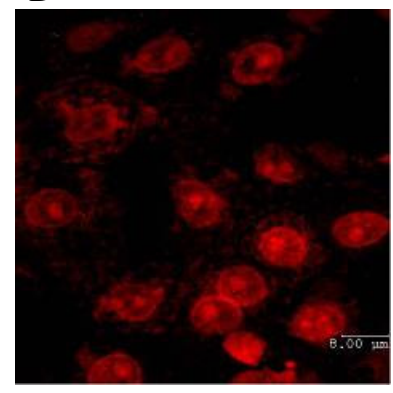

F

Fig. 2: Detection of HCV-RNA of either positive $(A, B)$ or negative $(\mathrm{D}, \mathrm{E})$ polarity in liver biopsy specimens from patients positive for anti-HCV antibodies and negative for serum HCV-RNA. (C,F) Absence of hybridization signals in healthy donor liver biopsies using either HCV-1 (C) or HCV-2 (F) probes (Bar $=4 \mu \mathrm{m}$ in $\mathrm{A}, \mathrm{B}, \mathrm{D}, \mathrm{E} ; 8 \mu \mathrm{m}$ in $\mathrm{C}, \mathrm{F}$ )

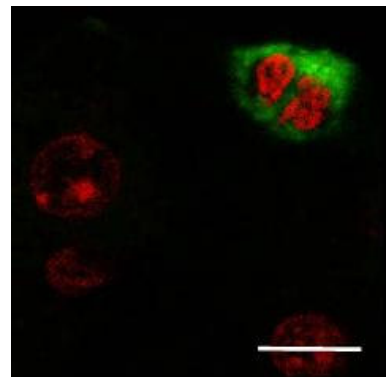

A

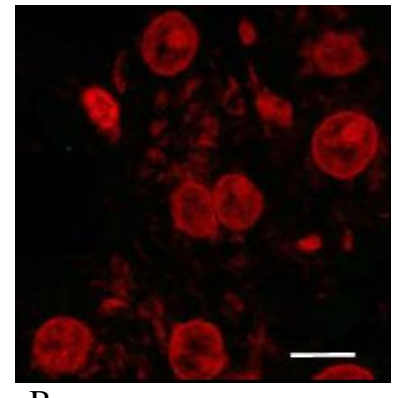

B
Fig. 3:Immunolabeling of $\mathrm{HCcAg}$ in liver biopsies from $\mathrm{HCV}$-infected patients. A) Immunostaining with the anti-HCcAg mAb (SS-HepC.1) B) Liver biopsies from healthy subjects, no immunostaining was observed using any of these mAbs. $($ Bar $=8 \mu \mathrm{m})$
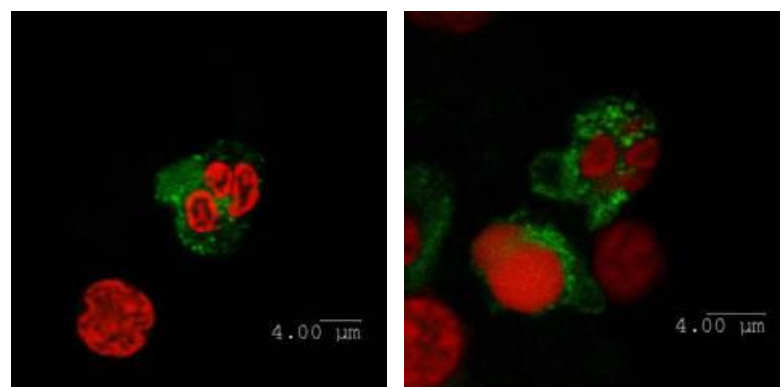

A

B
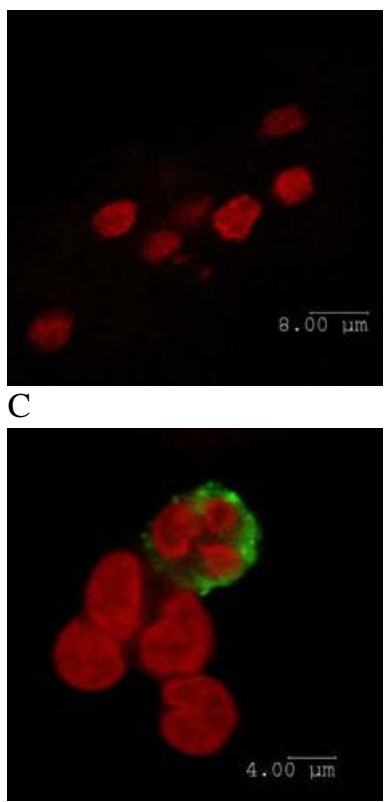

$\mathrm{E}$

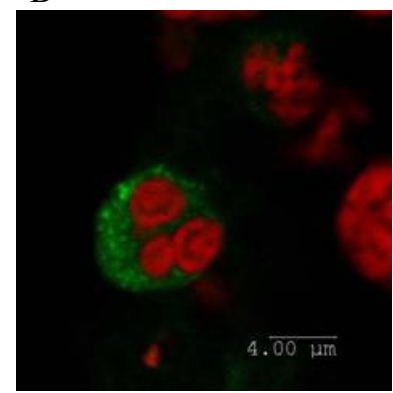

$\mathrm{D}$

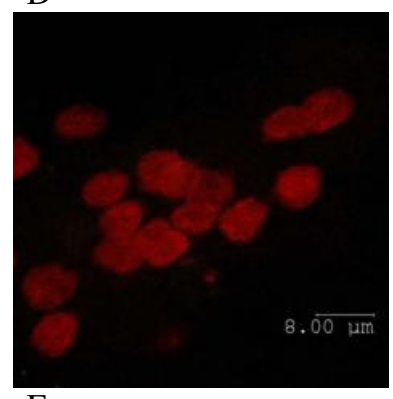

F

Fig. 4: Detection of HCV-RNA of either positive $(A, B)$ or negative (D,E) polarity in PBMC from patients positive for anti-HCV antibodies and negative for serum HCV-RNA. (C,F) Absence of hybridization signals in PBMC from healthy donor liver biopsies using either HCV-1 (C) or $\mathrm{HCV}-2$ (F) probes $(\mathrm{Bar}=4 \mu \mathrm{m}$ in A,B,D,E; $8 \mu \mathrm{m}$ in $\mathrm{C}, \mathrm{F}$ )

HCV-infected patients as indicated by dUTP incorporation. No sign of apoptosis was detected in PBMC from uninfected patients (Fig. 1E).

ISH analysis of liver biopsies showed both positive and negative strands of the HCV genome localized in the cytoplasm of hepatocytes from $\mathrm{HCV}$-infected patients (Fig. 2A,B,D,E), while no hybridization signals were observed in liver biopsy specimens from negative control subjects (Fig. 2C,F). It is interesting to note that some hepatocytes with positive ISH signals showed nuclear characteristics of apoptosis such as chromatin margination, condensation and fragmentation (Fig. 2A,B,D,E). These typical morphological changes of apoptotic cell death were also observed in some hepatocytes showing reaction products suggestive of $\mathrm{HCcAg}$ (Fig. 3A). No hybridization signals were 
observed in the liver biopsy specimens from the control subjects (Fig. 3B).

Remarkably, ISH analysis of PBMC detected the HCV-RNA of both positive and negative polarity in some cells showing a fragmented nucleic (Fig. $4 A, B, D, E)$. No positive signals were observed in PBMC from the control subjects (Fig. 4C,F).

\section{DISCUSSION}

There is evidence to suggest that apoptosis of liver cells may play a significant role in the pathogenesis of hepatitis $\mathrm{C}^{[14]}$. Apoptosis mediated by Fas or tumor necrosis factor (TNF) is a major pathway associated with liver injury and chronicity of HCV infection ${ }^{[15,16]}$. In addition, a recent study provides evidence for apoptosis and caspase 3 activation in hepatocytes during chronic $\mathrm{HCV}$ infection ${ }^{[13]}$. Previously, it has been shown that caspases are activated in human liver biopsies specimens from chronic hepatitis C patients ${ }^{[14]}$. Importantly, activation of caspase 3 and caspase 7 correlated significantly with inflammatory activity ${ }^{[14]}$.

Results obtained in this work suggest the presence of hepatic and PBMC apoptosis in patients positive for anti-HCV antibodies and negative for serum HCVRNA. Both DNA fragmentation by TUNEL assay and activation of caspase 3 were detected in hepatocytes from patients histologically confirmed as bearing chronic hepatitis or with abnormal ALAT or GGTP as well as in patients with no histological evidences of chronic hepatitis and normalization of transaminases. This partially agrees with a previous study showing that hepatocyte loss by apoptosis can occur in HCV-infected patients without overt biochemical changes ${ }^{[14,17]}$. Interestingly, a proportion of $\mathrm{HCV}$-infected hepatic and PBMC showed apoptotic nuclear changes. Remarkably, the intermediate replicative form of the $\mathrm{HCV}$ genome was detected in some of these apoptotic cells. Apoptotic nuclear changes included condensation, margination and segmentation of the nuclei into several fragments ${ }^{[13]}$. These results suggest that apoptosis of $\mathrm{HCV}$-infected hepatocytes may occurs either in the absence or in the presence of liver injury and inflammation.

A variety of apoptotic mechanisms might play a role in the elimination of infected cells. One explanation for the results observed in this work could be that the host immune response induces apoptosis of HCV-infected hepatocytes without liver injury. Previously, it has been shown that the prevalence of CD95 in HCV antigen-positive hepatocytes was significantly higher than in uninfected cells ${ }^{[18]}$. Moreover, it has been suggested that the degree of CD95 expression correlates with hepatocyte apoptosis ${ }^{[19]}$. The fact that neither CD95 expression nor the degree of liver injury correlate with intrahepatic viral load ${ }^{[17]}$ has supported the hypothesis of indirect immune-mediated mechanisms in hepatocyte apoptosis.
Thus, it has been proposed that CD95L-positive Tlymphocytes interact with CD95-bearing HCV-infected hepatocytes which may result in liver cell apoptosis leading to elimination of virus-infected cells.

Another explanation would be that $\mathrm{HCV}$ directly induces apoptosis of virus-infected cells in the absence of liver injury or inflammation. Several HCV proteins have been implicated in apoptosis regulation. $\mathrm{HCcAg}$ can either promote or inhibit apoptosis depending on experimental conditions and type of cell used, whereas both the NS3 and the NS5 proteins have antiapoptotic effects $^{[20,21]}$. Recently, Moorman et al reported that $\mathrm{HCcAg}$ expression leads to activation of caspase 8 and caspase 3 which was necessary and sufficient for apoptotic cell death ${ }^{[22]}$. In addition, it has been reported that $\mathrm{HCcAg}$ expressed in various cell lines localized in the mitochondria and causes mitochondrial injury, leading to oxidative stress ${ }^{[23]}$. Mitochondria dysfunction is an important factor in cytotoxicity, which may cause the cell to undergo apoptosis. Recently, $\mathrm{HCcAg}$ was shown to localize in the mitochondria of apoptotic hepatocytes, suggesting a direct effect of $\mathrm{HCcAg}$ on mitochondria ${ }^{[13]}$. Moreover, a recent study has shown that HCV induces apoptosis in persistently HCVinfected B-cell lines ${ }^{[24]}$. Thus, both immune-mediated reactions and direct cytopathic effects of $\mathrm{HCV}$ may be involved in the induction of apoptosis, which may interfere with viral replication. Indeed, a recent study has suggested that virus control is partially compatible with increased cell death of HCV-infected hepatocytes ${ }^{[25]}$.

On the other hand, regulation of cell cycle and apoptosis is essential to maintain cellular physiological conditions. Apoptosis appears to be more advantageous than necrosis for removing injured hepatocytes. The latter leads to liberation of the proteins and DNA and to the formation of oxygen radicals, cytokines and other inflammatory mediators, all of which may trigger potential secondary lethal responses within the organism. Extensive necrosis can damage the tissue structure and result in fibrosis. It thus seems logical that extensive necrosis and a lack of apoptosis can contribute to a more persistent or chronic inflammatory response.

However, several evidences support the hypothesis that under conditions of chronic liver damage and inflammation (in which immune-mediated mechanisms play a critical role) apoptosis may contribute to liver injury. Up-regulation of CD95 as well as induction of CD95L expression on T lymphocytes has been found to correlate with more severe inflammation in $\mathrm{HCV}$ infection $^{[26,27]}$. In addition, it has been shown that virusspecific immune response may not only target infected cells, but also noninfected hepatocytes via therelease of soluble proapoptotic mediators, such as CD95L and $\mathrm{TNF}^{[28]}$. Moreover, Bantel et al have shown that caspase activation is associated with inflammatory reactions, supporting the hypothesis of an immune- 
mediated mechanism for apoptotic liver cell damage in chronic $\mathrm{HCV}$ infection ${ }^{[14]}$.

On the other hand, induction of apoptosis in HCVinfected PBMC may have several implications. Although the anti-HCV immune response has not been studied yet in these patients, apoptosis of HCV-infected PBMC may impair the anti-HCV immune response and contribute to viral persistence. It has been observed that (in chronic HCV-infected patients) HCV infection induces CD95 expression on PBMC and that soluble CD95L leads to accelerated apoptosis of these CD95expressing cells ${ }^{[29]}$. In addition, it has been proposed that induction of $\mathrm{T}$-cell apoptosis in patients with chronic HCV infection contribute to sustained HCV infection ${ }^{[30]}$. Future studies of the relationship between apoptosis of HCV-infected PBMC and the host anti$\mathrm{HCV}$ immune response will contribute to elucidate some of the mechanisms of HCV persistence in infected patients.

Based on data shown in this study it is possible to suggest that under certain conditions $\mathrm{HCV}$ induces apoptosis in the absence of liver injury. Induction of apoptosis in HCV-infected cells may interfere with viral replication and host immune response, which may lead to undetectable levels of HCV-RNA in serum and impaired anti-HCV immune response.

\section{CONCLUSION}

Results obtained in this work suggest the presence of hepatic and PBMC apoptosis in patients positive for anti-HCV antibodies and negative for serum HCVRNA. Both DNA fragmentation by TUNEL assay and activation of caspase 3 were detected in hepatocytes and PBMC from patients histologically confirmed as bearing chronic hepatitis or with abnormal ALAT or GGTP as well as in patients with no histological evidences of chronic hepatitis and normalization of transaminases. In addition, HCV components were detected in hepatocytes and PBMC showing nuclear characteristics of apoptosis. Data suggest that under certain conditions $\mathrm{HCV}$ induces apoptosis in the absence of liver injury.

\section{ACKNOWLEDMENTS}

The authors thank Jesus Seone and Nilda Tamayo for their excellent technical assistance and Dr. Rafael F. Sanchez-Betancourt and Prof. Orlando J. Alvarez Guerrero for critical reading of the manuscript and for many helpful suggestions.

\section{REFERENCES}

1. Choo, Q.L., G. Kuo, A.J. Weiner, L.R. Overby, D.W. Bradley and M. Houghton. 1989. Isolation of a cDNA clone derived from a blood-borne non-A, non-B viral hepatitis genome. Science, 244: 359-362.
2. Alter, H.J. and M. Houghton. 2000. Clinical Medical Research Award. Hepatitis C virus and eliminating post-transfusion hepatitis. Nat. Med., 6: 1082-1086.

3. Grakoui, A., C. Wychowski, C. Lin, S.M. Feinstone and C.M. Rice, 1993. Expression and identification of hepatitis $\mathrm{C}$ virus polyprotein cleavage products. J. Virol., 67: 1385-1395.

4. Houghton, M., 2000. Strategies and prospects for vaccination against the hepatitis $\mathrm{C}$ viruses. Curr. Top. Microbiol. Immunol., 242: 327-39: 327-339.

5. Walker, F.M., M.C. Dazza, M.C. Dauge, O. Boucher, C. Bedel, D. Henin and T. Lehy, 1998. Detection and localization by in situ molecular biology techniques and immunohistochemistry of hepatitis $\mathrm{C}$ virus in livers of chronically infected patients. J. Histochem. Cytochem., 46: 653-660.

6. Castillo, I., M. Pardo, J. Bartolome, N. OrtizMovilla, E. Rodriguez-Inigo, S. de Lucas, C. Salas, J.A. Jimenez-Heffernan, A. Perez-Mota, J. Graus, J.M. Lopez-Alcorocho and V. Carreno, 2004. Occult hepatitis $\mathrm{C}$ virus infection in patients in whom the etiology of persistently abnormal results of liver-function tests is unknown. J. Infect. Dis., 189: 7-14.

7. Castillo, I., E. Rodriguez-Inigo, J. Bartolome, S. de Lucas, N. Ortiz-Movilla, J.M. Lopez-Alcorocho, M. Pardo and V. Carreno, 2005. Hepatitis C virus replicates in peripheral blood mononuclear cells of patients with occult hepatitis $\mathrm{C}$ virus infection. Gut, 54: 682-685.

8. Mazur, W., U. Mazurek, M. Jurzak, T. Wilczok, Z. Bulanowski and Z .Gonciarz, 2001. Positive and negative strands of HCV-RNA in sera and peripheral blood mononuclear cells of chronically hemodialyzed patients. Med. Sci. Monit., 7: 108-115.

9. Pham, T.N., S.A. MacParland, P.M. Mulrooney, H. Cooksley, N.V. Naoumov and T.I. Michalak, 2004. Hepatitis $\mathrm{C}$ virus persistence after spontaneous or treatment-induced resolution of hepatitis C. J. Virol., 78: 5867-5874.

10. Radkowski, M., J.F. Gallegos-Orozco, J. Jablonska, T.V. Colby, B. Walewska-Zielecka, J. Kubicka, J. Wilkinson, D. Adair, J. Rakela and T. Laskus, 2005. Persistence of hepatitis C virus in patients successfully treated for chronic hepatitis $\mathrm{C}$. Hepatology, 41: 106-114.

11. Falcón, V., N. Acosta-Rivero, M. Shibayama, J. Luna-Munoz, M. Miranda-Sanchez, M.C. de la Rosa, I. Menéndez, V. Gra, S. Dueñas-Carrera, G. García, E. Vilar, J. Silva, D. Lopez, M. GonzálezBravo, C. Fernández-Ortega, D. Casillas, J. Morales, J. Kouri and V. Tsutsumi, 2005. Evidences of hepatitis $\mathrm{C}$ virus replication in hepatocytes and peripheral blood monocuclear cells from patients negative for viral RNA in serum. Submited to Am. J. Infect Dis. 
12. Falcon, V., N. Acosta-Rivero, G. Chinea, J. Gavilondo, M.C. de la Rosa, I. Menendez, S. Duenas-Carrera, A. Vina, W. Garcia, B. Gra, M. Noa, E. Reytor, M.T. Barcelo, F. Alvarez and J. Morales-Grillo, 2003. Ultrastructural evidences of $\mathrm{HCV}$ infection in hepatocytes of chronically HCVinfected patients. Biochem. Biophys. Res. Commun., 305: 1085-1090.

13. Falcón, V., N. Acosta-Rivero, M. Shibayama, J. Luna-Munoz, M. Miranda-Sanchez, J. Gavilondo, M.C. de la Rosa, I. Menéndez, B. Gra, W. García, S. Dueñas-Carrera, J. Silva, G. Chinea, M. González-Bravo, F. Alvarez, J. Morales, J. Kouri and V. Tsutsumi, 2005. Detection of HCV components and pathological reactions in apoptotic hepatocytes from chronically HCV-infected patients. Am. J. Infect. Diseases, 1: 12-24.

14. Bantel, H., A. Lugering, C. Poremba, N. Lugering, J. Held, W. Domschke and K. Schulze-Osthoff, 2001. Caspase activation correlates with the degree of inflammatory liver injury in chronic hepatitis $\mathrm{C}$ virus infection. Hepatology, 34: 758-767.

15. Hayashi, N. and E. Mita, 1997. Fas system and apoptosis in viral hepatitis. J. Gastroenterol. Hepatol., 12: S223-S226.

16. Lau, J.Y., X. Xie, M.M. Lai and P.C. Wu, 1998. Apoptosis and viral hepatitis. Semin. Liver Dis. 18: 169-176.

17. Calabrese, F., P. Pontisso, E. Pettenazzo, L. Benvegnu, A. Vario, L. Chemello, A. Alberti and M. Valente, 2000. Liver cell apoptosis in chronic hepatitis $\mathrm{C}$ correlates with histological but not biochemical activity or serum HCV-RNA levels. Hepatology, 31: 1153-1159.

18. Hiramatsu, N., N. Hayashi, K. Katayama, K. Mochizuki, Y. Kawanishi, A. Kasahara, H. Fusamoto and T. Kamada, 1994. Immunohistochemical detection of Fas antigen in liver tissue of patients with chronic hepatitis $\mathrm{C}$. Hepatology, 19: 1354-1359.

19. Pianko, S., S. Patella, G. Ostapowicz, P. Desmond and W. Sievert, 2001. Fas-mediated hepatocyte apoptosis is increased by hepatitis $\mathrm{C}$ virus infection and alcohol consumption and may be associated with hepatic fibrosis: Mechanisms of liver cell injury in chronic hepatitis $\mathrm{C}$ virus infection. $\mathrm{J}$. Viral Hepat., 8: 406-413.

20. Hahn, C.S., Y.G. Cho, B.S. Kang, I.M. Lester and Y.S. Hahn. 2000. The HCV core protein acts as a positive regulator of fas-mediated apoptosis in a human lymphoblastoid T cell line. Virology, 276: 127-137.
21. Ray, R.B., K. Meyer and R. Ray, 1996. Suppression of apoptotic cell death by hepatitis C virus core protein. Virology, 226: 176-182.

22. Moorman, J.P., D. Prayther, D. McVay, Y.S. Hahn and C.S. Hahn, 2003. The C-terminal region of hepatitis $\mathrm{C}$ core protein is required for Fas-ligand independent apoptosis in Jurkat cells by facilitating Fas oligomerization. Virology, 312: 320-329.

23. Okuda, M., K. Li, M.R. Beard, L.A. Showalter, F. Scholle, S.M. Lemon and S.A. Weinman, 2002. Mitochondrial injury, oxidative stress and antioxidant gene expression are induced by hepatitis C virus core protein. Gastroenterology, 122: 366-375.

24. Sung, V.M., S. Shimodaira, A.L. Doughty, G.R. Picchio, H. Can, T.S. Yen, K.L. Lindsay, A.M. Levine and M.M. Lai. 2003. Establishment of Bcell lymphoma cell lines persistently infected with hepatitis $\mathrm{C}$ virus in vivo and in vitro: The apoptotic effects of virus infection. J. Virol., 77: 2134-2146.

25. Dahari, H., M. Major, X. Zhang, K. Mihalik, C.M. Rice, A.S. Perelson, S.M. Feinstone and A.U. Neumann, 2005. Mathematical modeling of primary hepatitis $\mathrm{C}$ infection: Noncytolytic clearance and early blockage of virion production. Gastroenterology, 128: 1056-1066.

26. Mita, E. and N. Hayashi, 1994. Role of Fas ligand in apoptosis induced by hepatitis $\mathrm{C}$ virus infection. Biochem. Biophys. Res. Commun., 204: 468-474.

27. Okasaki, M., K. Hino, K. Fujii, N. Kobayashi and K. Okita, 1996. Hepatic Fas antigen expression before and after interferon therapy in patients with chronic hepatitis C. Dig. Dis. Sci., 41: 2453-2458.

28. Ando, K., K. Hiroishi, T. Kaneko, T. Moriyama, Y. Muto, N. Kayagaki, H. Yagita, K. Okumura and M. Imawari, 1997. Perforin, Fas/Fas ligand and TNFalpha pathways as specific and bystander killing mechanisms of hepatitis $\mathrm{C}$ virus-specific human CTL. J. Immunol., 158: 5283-5291.

29. Taya, N., Y. Torimoto, M. Shindo, K. Hirai, C. Hasebe and Y. Kohgo, 2000. Fas-mediated apoptosis of peripheral blood mononuclear cells in patients with hepatitis C. Br. J. Haematol., 110: 89-97.

30. Nakamoto, Y., S. Kaneako and K. Kobayashi, 2001. Monocyte-dependent cell death of $\mathrm{T}$ lymphocyte subsets in chronic hepatitis $\mathrm{C}$. Immunol. Lett., 78: 167-174. 